\title{
Student Confidence as a Measure of Learning in an Undergraduate Principles of Horticultural Science Course
}

\author{
Candice A. Shoemaker ${ }^{1}$
}

ADDITIONAL INDEX WORDs. student learning outcomes, assessment, self-efficacy

Summary. Three to five student learning outcomes (SLOs) were written for each of seven units for the Principles of Horticultural Science course, the foundation course for all nine specializations within the undergraduate horticulture program at Kansas State University. The SLOs were then used as the framework for development of the course. A pre- and post-assessment was given to the students enrolled in the course in the fall semesters of 2005 through 2008 in an effort to assess if the SLOs were being met. The 50-item assessment asked students to record their confidence in ability to do something reflective of the SLOs such as "distinguish between transpiration and respiration" or "write a scientific plant name." The comparison of the student-reported confidence at the start of the course and their academic performance in the course were not correlated. Students' reported confidence at the conclusion of the course was correlated with their academic performance in 3 of the 4 years that were examined. Because confidence was correlated with academic performance in the course and a course would be considered a domain-specific construct, it is more likely that self-efficacy rather than confidence was impacted as the students moved through the course.

$\mathrm{M}$ any undergraduate horticulture programs offer an introductory or foundations course in horticulture or horticultural science. At Kansas State University, this course is HORT 201, Principles of Horticultural Science. HORT 201 is a foundation course that students in all nine specializations in horticulture are required to take and is a prerequisite for 15 upper division horticulture classes. The course is offered every fall semester, and enrollment over the past 8 years has ranged from 75 to 150 students. In addition to horticulture majors, students from all colleges across campus have enrolled in the course with most nonhorticulture students coming from other departments in the College of Agriculture and the disciplines of landscape architecture and business. The course consists of three 50-min lecture periods and one 2-h laboratory period per week. There is a required textbook and laboratory manual. Additional learning resources are made available through K-State Online, a web-based instructional platform.

Initially, based on the selected textbook (Preece and Read, 2005),

Department of Horticulture, Forestry, and Recreation Resources, Kansas State University, 2021 Throckmorton Plant Sciences Center, Manhattan, KS 66506

Contribution no. 10-281-J of the Kansas Agricultural Experiment Station, Manhattan.

${ }^{1}$ Corresponding author. E-mail: cshoemak@ksu.edu. the course was comprised of four units: 1) an introduction to horticulture: what it is, who is involved, what they do, and where it is going; 2) horticultural biology: how plants are named and categorized, plant structure and function, and how to apply this knowledge in horticulture; 3 ) horticultural environment: light, temperature, water, and soil-definitions of, their role(s) in plant growth, and how to apply this knowledge in horticulture; and 4) horticultural technology: applications of horticultural principles (propagation, postharvest, pest management, breeding, pruning) based on biological principles. Based on the units, seven course objectives were identified: 1) define horticulture and explain the relationship between horticulture and other fields of study; 2 ) explain the importance of horticulture to society and quality of life; 3) describe career and personal opportunities; 4) describe the general response of plants to major environmental variables; 5) give examples of practices/ techniques commonly used to produce a desired response in plants and explain how and why the practice/techniques yield the desired responses; 6 ) use your acquired knowledge to solve basic/ common horticultural problems; and 7) use your basic horticultural vocabulary in questions, answers, descriptions, definitions, and identifications.
As I began to teach this course, I was involved in writing our assessment of student learning plan for our undergraduate program in horticulture and participating in LEA/ $\mathrm{RN}^{\mathrm{TM}}$ (Learning Enhancement Action/Resource Network; Iowa State University, Ames, IA), a teaching workshop led by education professionals from Iowa State University that met monthly throughout the fall and spring semesters. As I learned more about assessment of student learning and student learning outcomes, I decided to use student learning outcomes (SLOs) as the framework for the design of HORT 201. Student learning outcomes state what students should know and be able to do as a result of their coursework (Maki, 2002). As a result, the course is now designed around seven units with each unit or topic within a unit having three to five targeted SLOs (Table 1). I then used the 49 SLOs to direct and focus my plans for the class and the students. For SLOs to be effective, the students must be aware of them and must be presented with several opportunities to develop the desired outcomes (Jenkins and Unwin, 1996; Maki, 2002). Each year I created more assignments, lecture activities, and online resources to reinforce the SLOs. For example, a unit overview handout was prepared for each unit with the SLOs listed at the top, the reading assignments for that unit were listed, key terms and phrases related to the SLOs were given, and several assignments that reinforced the SLOs were offered. An example of an assignment is: Using the student learning outcomes as your guide, write five test questions. The questions must be true/ false, matching, or multiple choice and cannot be all the same type of question. For each question indicate which of the student learning outcomes you are assessing.

The SLOs were presented as part of a PowerPoint (Microsoft, Redmond, WA) presentation in lecture on the first day of a unit and at the conclusion of a unit. Sample examination questions assessing each SLO in a unit were also presented at the conclusion of each unit. The SLOs were also used to guide preparation of examination questions. I would write examination questions that I thought would assess the student's achievement of the SLO. For example, for the student learning outcome "Given 
Table 1. Student learning outcomes for the seven units of an undergraduate principles of horticultural science course.

Unit

1. Overview of horticulture

2. Structure of higher plants

3. Naming and classifying plants

4. Plant growth and development:

Topic 1: Plant growth processes

4. Plant growth and development: Topic 1: Plant development

5. Plant propagation

\section{Student learning outcomes}

Given an overview of the horticulture industry, you will be able to:

1. Define sustainable agriculture, sustainable horticulture, and horticulture

2. Trace the historical events and their contribution to the rise of sustainable agriculture/horticulture

3. List and describe the subdivisions of horticulture

4. Identify the important cultures and individuals in the history of horticulture and their contribution

1. Given the parts of a plant cell and plant tissues, students will be able to identify the key functions and where they occur

2. Given diagrams of plants, students will be able to describe and recognize the vegetative and reproductive organs

3. Given vegetative and reproductive organs of a plant, students will be able to explain the basic functions

4. Given a horticultural situation, students will be able to describe the plants response based on the function of plant tissues and organs

5. Students will use the vocabulary of plant structure

1. Given the rules of nomenclature, students will be able to write a scientific plant name

2. Given a scientific plant name, students will be able to indicate the genus, specific epithet, and variety/cultivar of the plant

3. In the botanical classification system, students will be able to describe Gymnospermae and Angiospermae

4. In the botanical classification system, students will be able to list the principal differences between monocot and dicot plants

5. Describe the commonly used horticultural classification systems

Your study of plant growth processes will be complete when you can:

1. Describe the photosynthetic process and its relationship to horticultural practices, productivity, and environment

2. Describe the processes of respiration and photorespiration and their connection to water and oxygen needs and crop productivity

3. Explain how plants absorb water and nutrients

4. Trace the movement of water, food, and nutrients through plants (translocation) and how plants lose water (transpiration) and wilt

5. Explain specific ways growers may manipulate physiological processes for increased plant productivity and quality

Your study of plant development will be complete when you can:

1. Describe the stages in growth and development and their horticultural applications

2. Describe types of vegetative and reproductive development and their horticultural implications

3. Recognize the five categories of plant hormones and their roles in growth and development

4. Identify and describe the environmental factors that influence growth and development

Your study of plant propagation will be complete when you can:

1. Understand the purpose of propagation, the types of basic propagation, and the reasons for choosing each type

2. Explain the basics of sexual propagation from seed production through propagation by seeds

3. Explain the basics of asexual propagation

(Continued on next page) 
Table 1. (Continued) Student learning outcomes for the seven units of an undergraduate principles of horticultural science course.

\begin{tabular}{|c|c|}
\hline Unit & Student learning outcomes \\
\hline $\begin{array}{l}\text { 6. Plants and their environment: } \\
\text { Topic 1: Soils }\end{array}$ & $\begin{array}{l}\text { Your study of soils will be complete when you can: } \\
\text { 1. Explain how soils are formed } \\
\text { 2. Explain the chemical properties of soil and the influence those } \\
\text { properties have on plant growth } \\
\text { 3. Explain the physical properties of soil and the influence those } \\
\text { properties have on plant growth } \\
\text { 4. Describe the desired characteristics of growing media for containers }\end{array}$ \\
\hline $\begin{array}{l}\text { 6. Plants and their environment: } \\
\text { Topic 4: Water }\end{array}$ & $\begin{array}{l}\text { Your study of water will be complete when you can: } \\
\text { 1. Explain the properties of water and how they affect plant growth } \\
\text { 2. Explain how water moves in the plant } \\
\text { 3. Define transpiration and explain how light, temperature, wind, soil } \\
\text { moisture, and plant characteristics influence it } \\
\text { 4. Distinguish between xerophytes, mesophytes, and hydrophytes } \\
\text { 5. Explain how precipitation affects crop production } \\
\text { 6. Describe strategies for growing under low moisture conditions } \\
\text { 7. Explain how water moves through a soil }\end{array}$ \\
\hline
\end{tabular}

the rules of nomenclature, students will be able to write a scientific plant name," a likely multiple choice question would be "The correct way to write the scientific name of cultivar is" followed by multiple choices of a scientific plant name.

The use of SLOs for the development and implementation of HORT 201 was a new approach for me. The purpose of this study was to assess student confidence as a way to evaluate if the in-class activities, lectures,
Table 2. Mean scores of confidence to perform horticultural skills of students enrolled in an undergraduate principles of horticultural science course.

\begin{tabular}{lccccccc}
\hline Yr & $\begin{array}{c}\text { Mean pre-score } \\
(\mathbf{1}-\mathbf{5} \text { scale })^{\mathbf{z}}\end{array}$ & $\begin{array}{c}\text { Mean post-score } \\
(\mathbf{1}-\mathbf{5} \text { scale })^{\mathbf{z}}\end{array}$ & $\begin{array}{c}\text { Mean } \\
\text { difference }\end{array}$ & $\begin{array}{c}\text { Sample } \\
\text { size }(\mathbf{n o} \mathbf{)})\end{array}$ & $\mathbf{t}$ & df & $\boldsymbol{P}^{\mathbf{y}}$ \\
\hline 2005 & 2.11 & 3.60 & 1.49 & 75 & -15.196 & 74 & 0.000 \\
2006 & 1.97 & 3.96 & 1.99 & 48 & -18.176 & 47 & 0.000 \\
2007 & 2.04 & 4.08 & 2.04 & 52 & -20.946 & 51 & 0.000 \\
2008 & 2.02 & 3.89 & 1.87 & 53 & -17.623 & 52 & 0.000 \\
\hline
\end{tabular}

${ }^{\mathrm{z}} \mathrm{S}$ cores are based on a rating in which 1 = not confident at all, 2 = slightly confident, 3 = somewhat confident, $4=$ confident, 5 = very confident. Pre-scores are based on students' responses at the start of the course. Post-scores are based on students' responses at the end of the course.

'significance by a two-tailed $t$ test of significance. 
assignments, and examinations effectively targeted the SLOs such that the students were achieving the SLOs.

\section{Materials and methods}

To assess if the SLOs helped with student learning, a pre- and postassessment was given to the students on the first day of class and a day in the last week of class. The survey instrument consisted of 50 statements reflective of the SLOs. Students were asked to indicate how confident they were on that day to do the statement using a five-item Likert-type scale from not confident at all to very confident. For example, the students indicated how confident they were on that day to "distinguish a monocot from a dicot," "remove meristematic tissue from a growing plant," and "explain what a cultivar is." The pre- and postassessments were administered in 2005 (100 students), 2006 (92 students), 2007 (77 students), and 2008 (78 students). Pre- and post-assessments were pair-matched by a student identification number with 75 matched pairs in 2005 (75\% of enrolled students), 48 matched pairs in 2006 (52\% of enrolled students), 53 matched pairs in 2007 (69\% of enrolled students), and 53 matched pairs in 2008 (68\% of enrolled students). Students' final course grade, as a percent, was used as an indicator for learning.

Descriptive statistics, paired $t$ tests, Tukey's test, Duncan's multiple range test, analysis of variance, and correlational analysis were conducted using Excel 2007 (Microsoft) and SPSS (Version 18 for Windows; IBM SPSS, Chicago, IL). Confidence scores were calculated based on the five-item Likert scale. An average confidence score could range from 1 to 5 with 1 being the lowest possible score and 5 being the highest possible score. These scores are based on a rating in which $1=$ not confident at all, 2 = slightly confident, 3 = somewhat confident, 4 = confident, and $5=$ very confident as a response to the 50-item survey.

\section{Results}

Students reported slight confidence (close to two on the five-item Likert scale each year) at the start of the course and confidence (around four on the five-item Likert scale) at the end of the course in performing the 50 horticultural tasks on the day they completed the survey (Table 2).

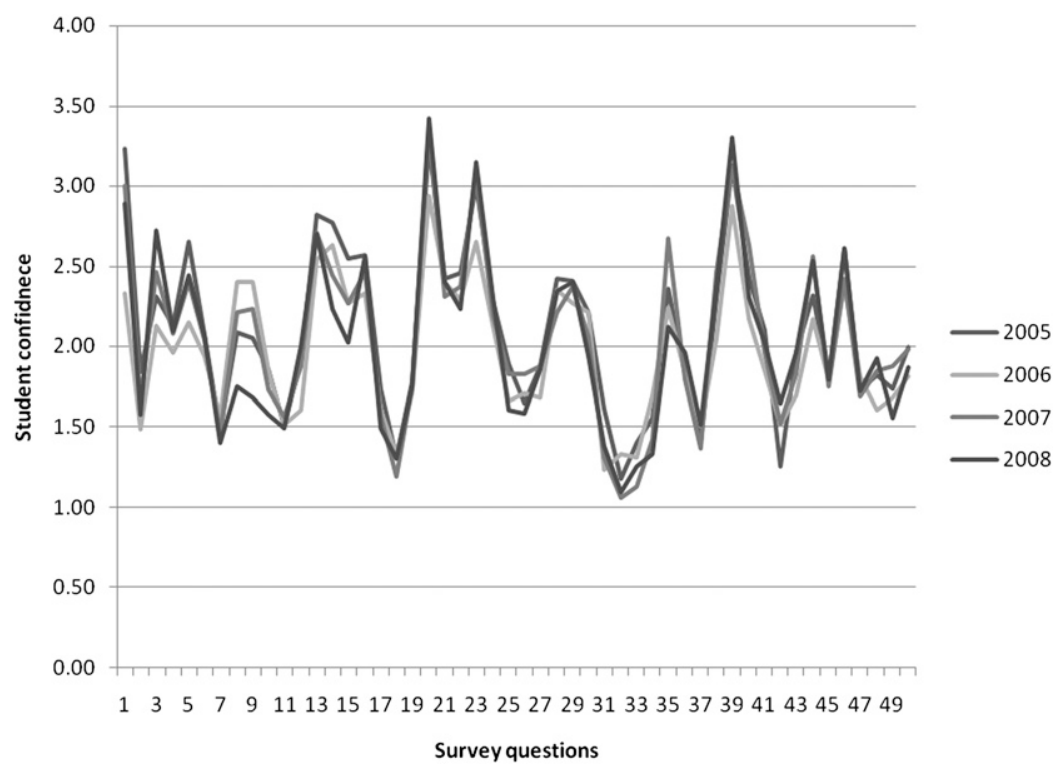

Fig. 1. Mean scores of confidence to perform $\mathbf{5 0}$ horticultural skills of students at the start of an undergraduate principles of horticultural science course. Scores are based on a rating in which $1=$ not confident at all, 2 = slightly confident, $3=$ somewhat confident, 4 = confident, and 5 = very confident. There was no difference in the students' reported confidence across all years at the start of the semester [analysis of variance: $F(3,196)=0.620, P=0.603$ ].

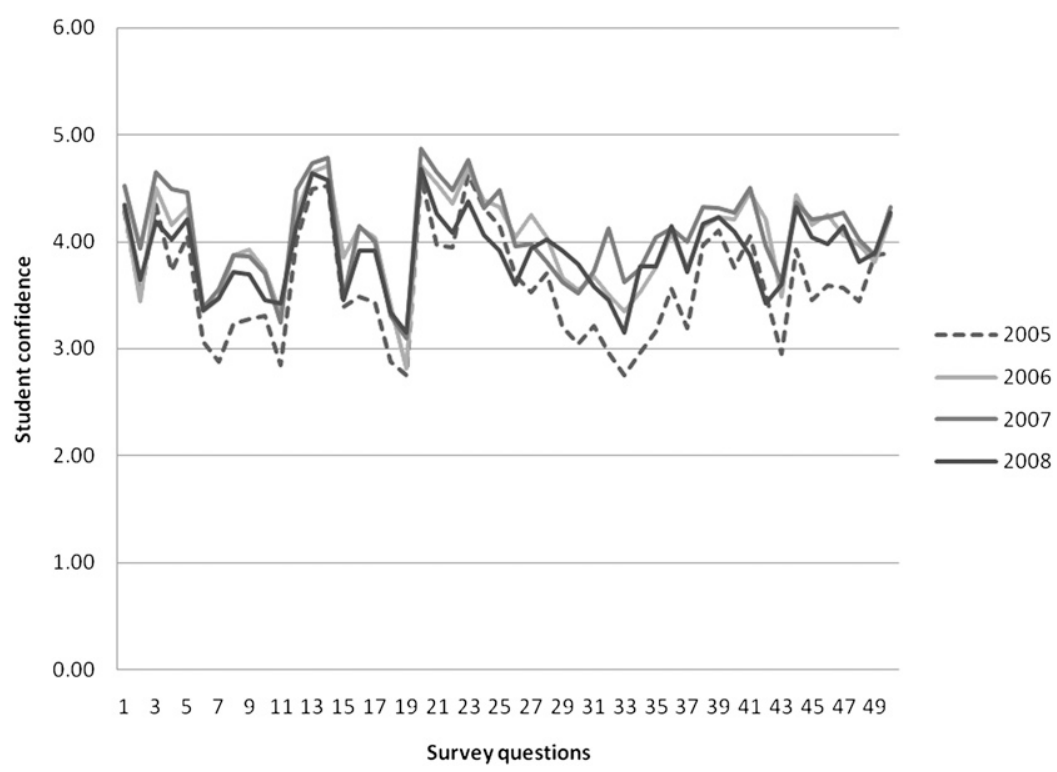

Fig. 2. Mean scores of confidence to perform $\mathbf{5 0}$ horticultural skills of students at the end of an undergraduate principles of horticultural science course. Scores are based on a rating in which 1 = not confident at all, 2 = slightly confident, 3 = somewhat confident, 4 = confident, and 5 = very confident. There was a difference in the students' reported confidence at the end of the semester [analysis of variance: $F$ $(3,196)-11.108, P<0.001]$. Students' confidence at the end of the semester in 2005 was significantly different from the other years (Tukey's honestly significant difference test at $P<0.05$ ).

The positive change in confidence was significant every year and the change averaged 1.49 to 2.04 (Table $2)$. There was a positive change preto post-assessment in all 50 statements in all years (data not shown).
There was no difference in the students' reported confidence across all years at the start of the semester $[F(3,196)=0.620, P=0.603]($ Fig. 1$)$; however, there was a difference at the end of the semester $[F(3,196)=11.108$, 
$P<0.001$ ] (Fig. 2). Students' confidence at the end of the semester in 2005 was significantly different from the other years $(P<0.05)$.

Average grade earned by semester increased from fall semester 2005 to fall semester $2008[F(3,339)=$ $2.033, P<0.10]$ (Fig. 3 ). In addition, there were differences in the percent of students earning each grade across years $[F(18,210)=132.366, P<0.05]$ (Fig. 4).

The comparison of the students' reported confidence at the start of the course and their academic performance in the course was not correlated (Table 3). Students' reported confidence at the conclusion of the course was correlated with their academic performance in the course in all years except 2006.

\section{Discussion}

Do those who know more also know that they know more? This is the question that inspired psychologists in the field of decision-making and education to study confidence. Know refers to performance accuracy, and knowing how much they know relates to confidence (Lichtenstien and Fischoff, 1977). Confidence is a measure of one's belief in one's own abilities and is considered a psychological trait that is related to but distinct from both personality and ability traits (Stankov and Lee, 2008). An interrelated construct is self-efficacy, which refers to a person's belief in one's capabilities to learn or perform behaviors at designated levels (Bandura, 1977, 1986). Much research shows that self-efficacy influences academic motivation, learning, and achievement (Pajares, 1996; Schunk, 1995). Although confidence and self-efficacy are interrelated, a defining aspect of selfefficacy, which distinguishes it from the more general construct of confidence, is its domain-specific nature. Thus, it is more likely that self-efficacy rather than confidence was impacted as students moved through HORT 201 because 1 ) all the activities associated with a course means a course is a domain-specific construct; and 2) the students' reported confidence at the end of the semester was correlated with academic performance (Table 3 ).

Because HORT 201 is the first horticulture course taken by most of the students, their report of slight confidence at the start of the semester is

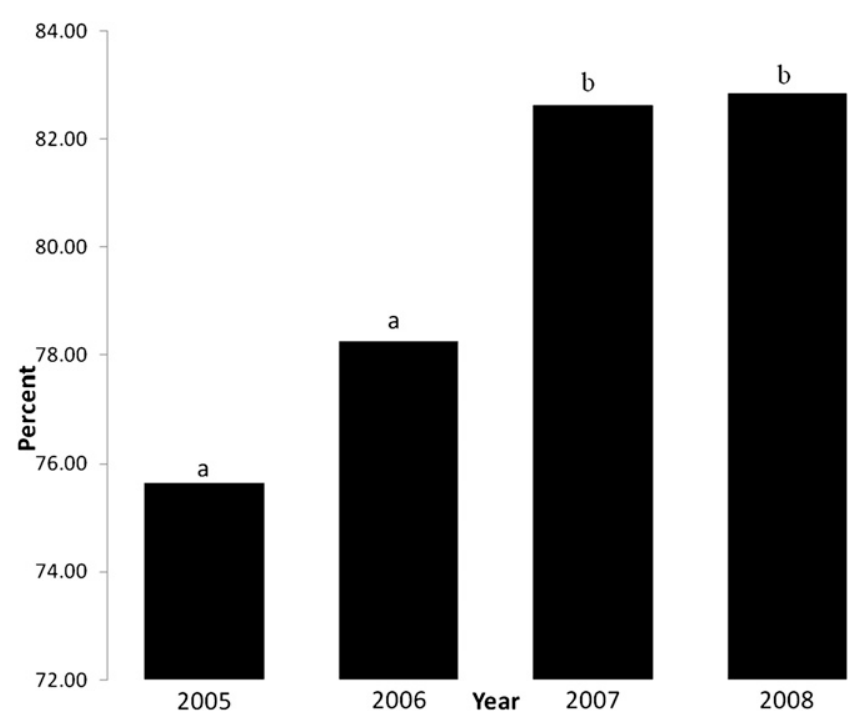

Fig. 3. Average semester grade for students enrolled in an undergraduate principles of horticultural science course. Bars with the same letter are not significantly different (Duncan multiple range test at $P=0.05$ ).

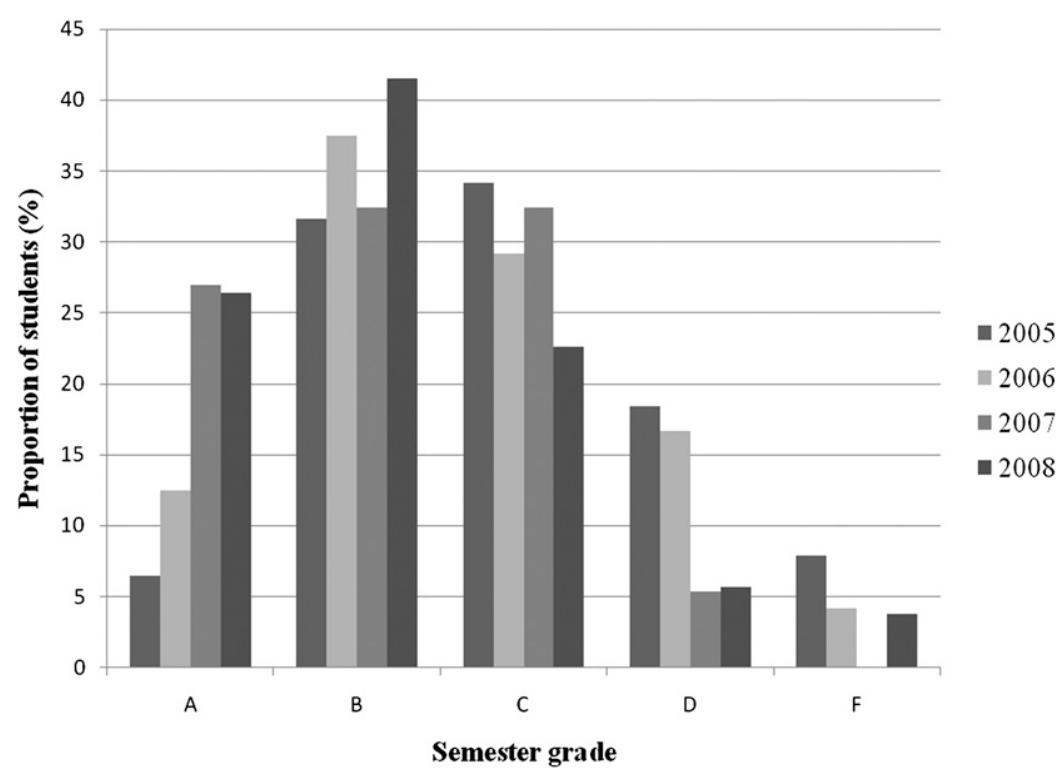

Fig. 4. Percentage of students earning each letter grade in an undergraduate principles of horticultural science course.

Table 3. Pearson correlation coefficients for students reported confidence to do $\mathbf{5 0}$ horticultural tasks at the start of an undergraduate horticultural science course and at the end of the course and their course grade.

\begin{tabular}{lccc}
\hline Yr & Pre-course & Post-course & Sample size (no.) \\
\hline 2005 & $0.159 \mathrm{NS}$ & $0.484^{* *}$ & 75 \\
2006 & $-0.103 \mathrm{NS}$ & $0.189 \mathrm{Ns}$ & 48 \\
2007 & $0.204 \mathrm{NS}$ & $0.293^{*}$ & 52 \\
2008 & $0.092 \mathrm{NS}$ & $0.449^{* *}$ & 53 \\
\hline
\end{tabular}

NS $=$ Nonsignificant, ${ }^{*}$ significant at the 0.05 level, ${ }^{*}$ significant at the 0.01 level.

realistic (Table 2; Fig. 1). As students move through the semester, they are affected by personal (e.g., goal setting, information processing) and situational influences (e.g., teacher feedback, grades) that provide them cues about how well they are learning. Self-efficacy is enhanced when students perceive 
they are performing well or becoming more skillful (Schunk and Pajares, 2002). Lack of success or slow progress will not necessarily lower selfefficacy if learners believe they can perform better by expending more effort or using more effective strategies (Schunk, 1995). One teaching strategy used in HORT 201 that may have targeted self-efficacy was the review of a unit's SLOs at the conclusion of each unit through sample examination questions reflective of each SLO. The SLO was presented followed by sample examination questions. Students were given time to consider each question before the answer was given. This activity was conducted in a fun and nonthreatening manner. From anecdotal reports from students, providing the example examination questions for each SLO helped the students understand what it meant to demonstrate achievement of the SLO and also helped them in preparing for examinations.

Instructional and other classroom processes' effects on self-efficacy have been researched. Processes beneficial for developing self-efficacy include "proximal and specific learning goals, strategy instruction and verbalization, social models, performance and attributional feedback, and performancecontingent rewards. These processes inform students of their capabilities and progress in learning, and this information motivates students to continue to perform well" (Schunk, 1995). Having three to five learning goals (SLOs) for each unit, featuring them repeatedly, and reinforcing them through lecture and assignment activities may have also targeted self-efficacy. This may also explain the improvement in overall academic performance from 2005 to 2008 (Figs. 3 and 4). There were more opportunities to affect self-efficacy because each year I built on the previous year, thus increasing opportunities to understand and demonstrate mastery of the SLOs through more assignments, lecture activities, and online resources. This may also explain why student confidence at the end of the semester was lower in the first year I implemented the SLOs than the other years (Fig. 2). Goalsetting and self-efficacy can strongly influence academic attainments (Zimmerman et al., 1992). Learning goals that are specific, short-term, and viewed as challenging but attainable enhance students' self-efficacy better than do goals that are general, longterm, or not viewed as attainable (Schunk, 1995).

Based on the pre- and postassessment results compared with the students' academic performance, the change in confidence was an indication of student learning. Using SLOs as a framework for the course was certainly a useful tool for me as an instructor. However, for SLOs to be effective for student learning, the students must be aware of them and must be presented with several opportunities to develop the desired outcomes. Ensuring that this was the case for HORT 201 inadvertently resulted in targeting domain-specific mediators of self-efficacy that ultimately resulted in improved student learning.

\section{Literature cited}

Bandura, A. 1977. Self-efficacy: The exercise of control. Freeman, New York, NY.
Bandura, A. 1986. Social foundations of thought and action: A social cognitive theory. Prentice Hall, Englewoods Cliffs, NJ.

Jenkins, A. and D. Unwin. 1996. How to write learning outcomes. 15 Mar. 2010. <http://www.ncgia.ucsb.edu/education/ curricula/giscc/units/format/outcomes. html>.

Lichtenstien, S. and B. Fischoff. 1977. Do those who know more also know more about how much they know? Organizational Behavior Human Performance 20: 159-183.

Maki, P.L. 2002. Developing an assessment plan to learn about student learning. J. Acad. Librarianship 28:8-13.

Pajares, F. 1996. Self-efficacy beliefs in achievement settings. Rev. Educ. Res. 66: 543-578.

Preece, J.E. and P.E. Read. 2005. The biology of horticulture. Wiley, Hoboken, NJ.

Schunk, D.H. 1995. Self-efficacy and education and instruction, p. 281-303. In: Maddus, J.E. (ed.). Self-efficacy, adaptation, and adjustment: Theory, research, and application. Plenum Press, New York, NY.

Schunk, D.H. and F. Pajares. 2002. The development of academic self-efficacy, p. 15-31. In: Wigfield, A. and J. Eccles (eds.). Development of achievement motivation. Academic Press, San Diego, CA.

Stankov, L. and J. Lee. 2008. Confidence and cognitive test performance. J. Educ. Psychol. 100:961-976.

Zimmerman, B.J., A. Bandura, and M. Martinez-Pons. 1992. Self-motivation for academic attainment: The role of selfefficacy beliefs and personal goal-setting. Am. Educ. Res. J. 29:663-676. 